\title{
Revenue management: resolving a revenue optimization paradox
}

\section{Revenue management}

\author{
Tony S.M. Tse
}

School of Hotel and Tourism Management, The Hong Kong Polytechnic University, Hong Kong, and

Yiu Tung Poon

Department of Mathematics, Iowa State University, Ames, Iowa, USA

Received 22 April 2011

Revised 31 July 2011

3 October 2011

5 November 2011

Accepted 20 November 2011

\begin{abstract}
Purpose - The objectives of this study are to investigate the relationship between hotel room demand and room rates, and to find a viable solution for the optimal room rate that maximizes the total profit.
\end{abstract}

Design/methodology/approach - There are various studies in the literature on how room rates affect profitability, and how the optimal room rate that maximizes the total revenue can be determined. Most of these studies assume an algebraic relationship between room rates and room demand, and obtain the optimal solution by applying calculus to the revenue or profit function. This study adopts the alternative approach of using a model with a demand function that has been shown to be a superior causal forecasting model in some markets, and develops a new method to optimize the total profit.

Findings - The traditional method of applying calculus to the profit function based on a causal forecasting model leads to unrealistic solutions. This gives rise to the paradox that, on the one hand, there is a superior causal forecasting model based on room rates, but on the other hand, the traditional method does not yield a realistic solution for room rate optimization. This study analyzes the underlying causes of this paradox and proposes a method to resolve it.

Practical implications - The findings can be used by hotels to fine-tune the room rates determined by conventional methods to arrive at a realistic and definitive value for the optimal room rate.

Originality/value - This study highlights the problems that arise with the traditional method of applying calculus to revenue and profit optimization and proposes a new method to resolve it.

Keywords Hotels, Hotel revenue management, Room rates, Hotel demand, Optimization, Optimization techniques, Forecasting

Paper type Research paper

\section{Introduction}

Revenue management, or yield management, in the hospitality industry has been an academic research topic for a long time. According to Relihan (1989), yield management began as the practice of bringing hotel room pricing into alignment with actual market forces, thereby striking a balance between supply and demand through the adjustment of room rates. Although a hotel derives revenue not only from rooms but also from food and beverage and events, room sales usually account for the bulk of the revenue. For example, room sales account for 66.5 percent of the total hotel revenue in the US (PKF, 2005), 52.0 percent in China (Horwath HTL, 2009), and 64.4 percent in Hong Kong (Hong Kong Tourism Board, 2008). In this study, discussion of revenue

This research project is funded by The Hong Kong Polytechnic University's Departmental General Research Fund 2009/2010.

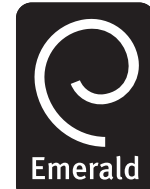

Emerald

International Journal of Contemporary Hospitality Management

Vol. 24 No. 4, 2012 pp. 507-521

(C) Emerald Group Publishing Limited 0959-6119 DOI 10.1108/09596111211226798 
IJCHM

24,4

508 management considers rooms only, and the objective of revenue management in a hotel is assumed to be the maximization of profit from room sales.

Revenue management is an integrated and systematic approach to revenue maximization through the manipulation of the rates offered to customers (Sanchez and Satir, 2005). Obviously, the decision about hotel room rates has a significant effect on revenue and profit. According to Helsel and Cullen (2006), revenue management deals with segmentation, demand forecasting, revenue strategy, operational forecasting, interdepartmental integration, strategic pricing, inventory control strategies, and internal performance analysis. The room rate strategy is one of the most important strategies set by hotel operators (Pan, 2007), and comprises the allocation of room inventory to be sold at a certain room rate, the allocation of room inventory to different distribution channels, an overbooking policy, and a cancellation policy. Revenue management decisions are complicated by having to consider different room types, different contractual room rates, and different durations of stay. These decisions are difficult to make because of the many uncertainties involved in the decision process, including uncertainties about visitor arrivals to a destination, hotel room demand, the elasticity of hotel room demand, the incidence of no-shows, and competitor pricing. In practice, a hotel manager must make assumptions about these uncertainties and then make revenue management decisions accordingly. A review of the literature indicates that hotel managers are informed by three types of discussions about revenue management.

The first type of discussion is conceptual and qualitative in nature. The second type is based on operations research and is quantitative in nature. The third type is related to the forecasting of demand for hotel rooms, cancellations, and no-shows. This study reviews and evaluates all three discussions to pave the way for the development of a formula for deriving the room rate that maximizes the total profit. The objectives of this paper are to investigate the relationship between hotel room demand and room rates, and to find a viable solution for the optimal room rate that maximizes the total profit. This study applies mathematical analysis to an established econometric forecasting model to determine the optimal room rate.

The following sections review and evaluate the three types of discussions about hotel revenue management, conceptually develop a method to arrive at the optimal room rate that maximizes the total profit, and provide an example to illustrate the method.

\section{Conceptual discussion of revenue management}

Cross (1997) advocated revenue management as a perspective on the way in which a hotel conducts business that focuses on revenue. He suggested using a nine-step process to ensure the successful implementation of revenue management in a hotel. The nine steps are:

(1) evaluate your market needs;

(2) evaluate your organization and process;

(3) quantify the benefits;

(4) enlist technology;

(5) implement forecasting;

(6) apply optimization; 
(7) create teams;

(8) execute, execute, execute; and

(9) evaluate success.

\section{Revenue management}

Cross' research drew attention to several additional areas of revenue management other than sales, including accurate forecasting, identifying variable costs, and determining the optimal room rate.

Although determining the room rate is key to revenue management, Orkin (1998) recognized that revenue management hinges on the estimation of future demand, and that hotel operators must try to make as accurately estimations as possible in a scientific manner. Orkin discussed the concept of unconstrained demand and referred to it as the level of room-nights that guests would reserve in the absence of any limitations or constraints, and pointed out that a hotel could never be certain if a reservation request was genuine and that tracking booking denial is very difficult. These difficulties notwithstanding, the study advocates forecasting hotel room demand in a scientific manner as the foundation for the optimization process.

Choi and Kimes (2002) suggested that hotel managers should evaluate the effects of distribution channels on their revenue management. They extended the revenue management forecasting and optimization methods to consider the effects of distribution channels, and used a computer simulation to test the performance of the extended methods. They concluded that optimizing by rate, length of stay, and distribution channel did not make a significantly greater contribution than optimizing by rate and length of stay only. This reinforces the point that room rate is the most important element of optimization.

In a review of revenue management studies, Kimes (2003) stressed that a hotel should gain a better understanding of price elasticity and price their rooms according to different distribution channels and the impact of different rate-quoting strategies on customers. She also highlighted the gap in the knowledge of the relationship between demand for hotel rooms and room rates. This study addresses this knowledge gap.

Sanchez and Satir (2005) examined two reservation modes, online and offline, in a hotel group and compared their yield management performance over a two-year period. They discovered that the online mode facilitated a higher revenue return. However, the determination of the optimal room rate was not discussed, despite its central importance. In contrast, this study specifically develops a method to determine the optimal room rate.

Enz et al. (2009) systematically analyzed pricing and occupancy in the US hotel industry for the period 2001 to 2007 , and provided insights on revenue management. They advised raising room rates in relation to those of competing hotels, rather than lowering them, because a higher RevPAR (revenue per available room) fully makes up for the loss in occupancy. However, they did not answer the question of what the optimal room rate should be.

Cross et al. (2009) advocated a "customer-centric" approach as opposed to an "inventory-centric" approach to revenue management. A "customer-centric" approach to revenue management means applying demand-forecasting capabilities to create an integrated demand planning cycle. Customer-centric revenue management means that during peak periods, inventory will be set aside to accommodate certain loyal customer segments. The authors pointed out that in practicing revenue management, rooms are 
IJCHM

24,4

510

not sold at a certain rate and kept to accommodate customers who will pay a much higher rate at a later stage. This is an important judgment that will always be needed in practice anyway. The authors asserted that it is still necessary to determine the optimal room rate in a scientific manner before making this judgment, which is indeed the approach adopted in this study.

Cross et al. (2009) further noted that forecasting is not just about numbers, but is also a tool for painting an accurate picture of customer demand in the long term. They suggested that managers should avoid the practice and fallacy of basing forecasts on budgets, because budgets are built on expectations and are not indicative of what is really happening. It can be argued that what the industry needs is an intelligent forecasting system that can be applied to revenue management. Despite the advances in forecasting, hotel demand forecasting remains not well developed for the purposes of room rate optimization and profit maximization, as illustrated by the literature review. This study addresses the core issue by applying mathematical analysis to an established forecasting model to determine the optimal room rate.

Schwartz and Chen (2010) examined how an intensified room rate signal affects customer perceptions, their propensity to book, and consequently hotels' revenue maximization. They suggested that the higher the room rate, the higher customers' quality expectations and assessment of the prospects of being offered a better (lower) rate in the future. They also found that the higher the room rate, the lower the perception of the sell-out risk. However, like most other studies on revenue management, the authors offered no guidance on how the optimal room rate might be determined.

The conceptual discussion outlined in this review has been important in directing research toward revenue management and identifying the key areas to be explored. However, few studies in this stream of the literature cover the determination of the optimal room rate to maximize the total profit.

\section{Operations research in revenue management}

This section discusses how operations research approaches revenue management in a quantitative manner and the limitations of this approach.

Bitran and Mondschein (1995) framed the revenue management question as follows. Every time a customer requests a room, the hotel manager must decide whether or not to rent it to the customer. In arriving at this decision, the hotel manager must consider the number of reservations already made and the potential demand from walk-ins in the future. The operational research model assumes that the arrival of customers follows a Poisson distribution and handles multiple types of rooms with the possibility of downgrading. The model assumes the stochastic and dynamic arrival of customers from different classes and calculates the expected value of a room in the future. To calculate the expected value, a hotel manager must determine the price associated with a particular class of customer, the rejection cost associated with a particular class of customer, the total number of rooms available for each room type, the planning horizon, and pending reservations for each class of customer. The model states that the hotel should rent the room if the price plus the rejection cost of the room is greater than or equal to the room's expected value, and it should reject the customer if the price plus rejection cost of the room is smaller than the room's expected value.

Bitran and Mondschein's (1995) approach is scientific and deterministic, but a major shortcoming of this operational research model is that it treats the room rates as given. 
In reality, hotel room rates are not fixed and are the most important variable that a hotel manager can adjust to optimize the total revenue. Indeed, the most important decision in revenue management is how much a room should cost, and not whether to rent a room or not at a certain rate.

Weatherford (1995) studied how length of stay affects hotel revenue, and found that incorporating length of stay into room allocation decisions allows hotels reap up to an additional 2.94 percent in revenue, depending on the occupancy levels for their properties or stay nights and the percentage of guests staying for more than one night.

Baker and Collier (1999) considered the essence of yield management to be reservation control, or the systematic acceptance or rejection of reservation requests to maximize the benefit to the hotel. Again, their discussion focuses on the acceptance-rejection decision, rather than the dynamic decision as to how much a room should be charged and the price elasticity.

Badinelli (2000) adopted a different approach of developing an operational research model to solve the hotel yield management problem. The model sets out to maximize profit by determining the price of a hotel's product/service package. The beauty of Badinelli's model is that it computes the prices that should be quoted for different market segments in a given period to maximize the total revenue. However, the model assumes that forecasting has been carried out and that estimates of the probability distributions of demand from each market segment during each interval within the planning horizon are available. Obviously, this is an important assumption that determines the validity and accuracy of the model, but the assumption is questionable. This study seeks to develop a reliable method of forecasting hotel room demand and apply it to hotel revenue management. Badinelli acknowledged that a persistent difficulty in studying the yield management problem is that most reservations systems capture sales data but not demand data. In other words, the accurate forecasting of hotel room demand is the missing link in yield management.

Lai and $\mathrm{Ng}$ (2005) offered a different approach to hotel optimization by investigating the allocation of rooms according to different check-in check-out periods. They proposed a network optimization model with a stochastic programming formulation to capture the randomness of the unknown demand. The formulation is transformed into a robust optimization model. The model is then converted into a standard linear programming form that can be solved by a linear modeling package where the weighting parameters are assigned by the decision maker. The limitation of this approach is that both revenue and demand are treated as unrelated stochastic variables, whereas in reality both are related to price, but the model does not take this very important connection into consideration. In addition, the model does not explain how the weighting parameters are determined.

Rest and Harris (2008) advocated a decision rule indicating the direction in which the profit will change as a result of a change in price. They used algebra and calculus to demonstrate that, with knowledge of how room demand is affected by price changes, it is possible to determine when an increase in room price will result in an increase or decrease in profit, and when a decrease in room price will result in a decrease or increase in profit. Their study introduced the concept of the "contribution margin ratio" and compared it with the price elasticity of demand as the basis for making pricing decisions. The decision model relies on knowledge of how the room demand is affected by price changes, which the researchers themselves acknowledged as being limited for 
IJCHM

24,4

512

managerial use and giving imperfect mathematical results. Another shortcoming of the decision model is that it does not definitively state what the optimal room rate should be.

Like the conceptual discussion, operations research covers many important aspects of revenue management, but seldom touches the topic of determining the optimal room rate and maximizing the total profit.

\section{Forecasting and revenue management}

The foregoing sections reveal the importance of having an accurate forecasting model of revenue management. Broadly speaking, there are two types of hotel demand forecasting: time series analysis and econometric modeling. Time series analyses involve forecasting models that extrapolate historic demand trends into the future without considering the underlying causes of those trends, which are assumed to be non-causal in nature (Song et al., 2003). Econometric models, in contrast, are carefully constructed based on econometric theory, and are thus causal in nature. Such models allow researchers to assess the manner in which customers will respond to changes in the determining factors by examining the estimated demand elasticities (Song et al., 2003).

Rajopadhye et al. (2001) recognized that many hotel revenue management systems deal with the optimization problem, but there has been little published work on the forecasting aspect. They used historical data obtained from a hotel and the Holt-Winters smoothing method to forecast the demand for rooms at a hotel for each arrival day. The forecast was based on past observations, with recent observations being given more weight and observations further in the past less weight. The limitation of the model is that it deals with the forecasting of unconstrained hotel room demand, which is the number of rooms that can be rented if there are no capacity or pricing constraints. The assumption of unconstrained hotel room demand is obviously questionable in the real world. In addition, the focus of their study was hotel room demand forecasting, and they did not explain how the model might be applied to room rate optimization.

Weatherford et al. (2001) examined forecasting for hotel revenue management and found that most major hotels use a linear programming model that requires detailed forecasts by day of arrival, length of stay, and rate category. Some hotels forecast overall arrivals and then develop detailed length of stay and rate category forecasts by applying historical probability distributions to the arrival forecast. Others forecast arrivals by rate category or length of stay, and then apply the appropriate probability distribution to derive a detailed forecast. Some hotels develop detailed arrivals forecasts by rate category and length of stay together. As with earlier studies, however, only forecasting was discussed, and room rate optimization and profit maximization were neglected.

Weatherford and Kimes (2003) acknowledged that forecasting is the key driver of revenue management, and that without accurate forecasts, the rate and availability recommendations produced by revenue management systems may be inaccurate. By making accurate and stable forecasts, hotels can more effectively use their revenue management systems, leading to better staffing, purchasing, and budgeting decisions. They tested seven forecasting methods: simple exponential smoothing, moving average, linear regression, logarithmic linear regression, the additive method, the 
multiplicative method, and Holt's double exponential smoothing. They concluded that the best forecasting method varies by property, rate category, and length of stay, and that there is no single "best" method. However, they failed to elaborate on the relationship between demand forecast and room rates.

Steed and $\mathrm{Gu}$ (2009) explored US hotel management company forecasting and budgeting practices, and found seven common practices that create a potential environment for budgeting and forecasting inaccuracy:

(1) the linking of bonuses to budget achievement;

(2) the lack of a sophisticated regional forecast;

(3) the utilization of budgets as a standard for actual performance;

(4) numerous levels of budget review;

(5) the amount of time spent on an annual budget;

(6) the combination of a top-down and bottom-up approach; and

(7) the utilization of spreadsheets and transmitted technology.

The foregoing review of research in this stream shows that few studies of hotel demand forecasting focus on the optimization of room rates. The research is more concerned with forecasting per se and is not related to optimization. Few of the relevant studies describe a mathematical relationship between demand and price, meaning that the optimization of room rates cannot be performed. Intuitively, it could be said that room rates should be adjusted downwards if the demand is forecasted to be low, and upwards if the demand is forecasted to be high. However, adjusting room rates downwards or upwards may not lead to revenue increases. Revenue dynamics depend on the elasticity of demand. If the demand is price elastic, then a reduction in price will lead to a revenue increase. If the demand is price inelastic, then a reduction in price will lead to a decline in revenue. Thus, a more systematic and scientific approach than intuitive reasoning is needed to address the issue of demand elasticity in revenue management. A more robust forecasting method using econometric models is considered in the next section.

\section{Hotel demand forecasting using econometric models}

The foregoing discussion shows how the conceptual discussion, operations research, and forecasting have contributed to the study of revenue management and their limitations. However, none of the various models discussed are able to determine the optimal room rate, because they do not elaborate on the relationship between room demand and room rate. It is clear that the development of a good forecasting system is vitally important for successful revenue management implementation (Talluri and Ryzin, 2005), and the foregoing review clearly points to the necessity of establishing accurate forecasting in relation to room pricing if revenue management is to become more vigorous, deterministic, and applicable.

$\mathrm{Gu}$ (1997) proposed using a simple linear model to depict the relationship between demand for rooms and room rates, and used this relationship to maximize the daily room revenue as:

$$
D(r)=a-\beta r
$$


IJCHM

24,4

514

where $D(r)$ is the daily demand for rooms, $r$ is the room rate, $\alpha$ is the potential demand for rooms when $r$ is zero, and $\beta$ is a measure of the price sensitivity of the room demand. The daily room profit $\pi$ is the product of the rooms demanded $D(r)$ and the room rate $r$, less the costs related to operations $C$, as follows:

$$
\pi(r)=D(r) r-C
$$

$\mathrm{Gu}$ (1997) further showed that to maximize the daily room profit $\pi$, the room rate $\mathrm{r}$ must be set to $(\alpha+\beta \nu) /(2 \beta)$, where $\nu$ is the variable cost per room sold, and $\alpha$ and $\beta$ are parameters that can be estimated by using regression based on the demand equation with observed daily rooms sold and room rates in the past.

The main problem with this model is that it assumes a linear relationship between room rates and room demand, which is not a realistic global representation of price response (Phillips, 2005).

According to Song et al. (2009), a superior forecasting method to the linear model of tourism demand analysis is the power model, which outperforms the linear model in terms of expected coefficient signs and the statistical significance of the coefficients (Witt and Witt, 1995, as cited by Song et al., 2009). The power model for the price-response function, or demand function, can be presented as follows:

$$
D(r)=A r^{\beta}
$$

where $D(r)$ is the demand for a hotel room in a specific category at room rate $r$. A and $\beta$ are constants. Note that $\beta<0$ because the demand decreases as $r$ increases.

The use of the power model in tourism forecasting is an emerging method that deserves attention. Song et al. (2003) applied the power model to generate forecasts of international tourism arrivals from 16 major source markets to Hong Kong for the period 2001 to 2008. The power model was also used in the Hong Kong Tourism Demand Forecasting System (2009) to forecast demand for different categories of hotel rooms among residents of nine major origin countries up to 2015. In a recent study, Song et al. (2011) rendered the power model dynamic by including lagged dependent variables that take into account the effect of room rates on future demand. This dynamic model resembles the real situation in hotels, and lends itself to more sophisticated optimization.

\section{Applying mathematical analysis to the econometric model}

The method of applying calculus to revenue and profit maximization has been established in business mathematics for a long time. This section highlights the problems that may arise with the traditional method of applying calculus to revenue and profit optimization, and proposes a new method of optimization.

Suppose that the demand function is given by the power model described in the previous section. Using the formula "revenue equals price times demand," the revenue function is then given by:

$$
\begin{gathered}
R(r)=D(r) r \\
=A r^{\beta} r \\
=A r^{\beta+1}
\end{gathered}
$$


Note that this revenue function is monotonic in $r$, that is, $R(r)$ is an increasing (respectively, decreasing) function of $\mathrm{r}$ if $\beta>-1$ (respectively, $\beta>-1$ ). This monotonic property is illustrated in Figure 1.

In presenting the power model (also known as the constant-elasticity price-response function), Phillips (2005) and Talluri and Ryzin (2005) both point out that this monotonic property means that a seller can maximize revenue by either increasing the price to infinity or dropping it as close to zero as possible. This is obviously an unrealistic scenario, and poses a problem for revenue optimization. There appears to be a paradox in that, on the one hand, we have a superior causal forecasting model based on room rates, but on the other hand, the model does not give a realistic solution for the optimal room rate. In fact, the problem lies not only in the monotonic nature of the revenue function, but also arises when the traditional method of applying calculus is used to optimize profit. Consider the profit function of the foregoing power model with a fixed cost $\mathrm{F}$ and a variable cost $v$. In this case, the profit function is given by:

$$
\pi(r)=D(r)(r-v)-F=A\left(r^{\beta+1}-v r^{\beta}\right)-F
$$

For $\beta<-1$ the traditional calculus method shows that $\pi(r)$ has a maximum at $r=\frac{\beta v}{\beta+1}$. This solution can also be deduced from the formula relating the optimal price to the price elasticity and cost developed by Phillips (2005, p. 65):

$$
p^{*}=\frac{e\left(p^{*}\right)}{e\left(p^{*}\right)-1} C
$$

where $p^{*}$ is the optimal price, $e\left(p^{*}\right)$ is the elasticity, and $c$ is the unit cost.

Phillips (2005) suggests that formula (1) can be used to calculate the optimal price when the elasticity is constant. Mathematically, the model with constant elasticity is the power model already described, where $e\left(p^{*}\right)=-\beta, c=v$ and $p^{*}$ is the optimal rate for $r$. If formula (1) is applied to calculate the optimal price of a hotel room, the solution is unrealistic, as illustrated by the following situations:

(1) If the elasticity is less than 1 , then the optimal room rate is negative.

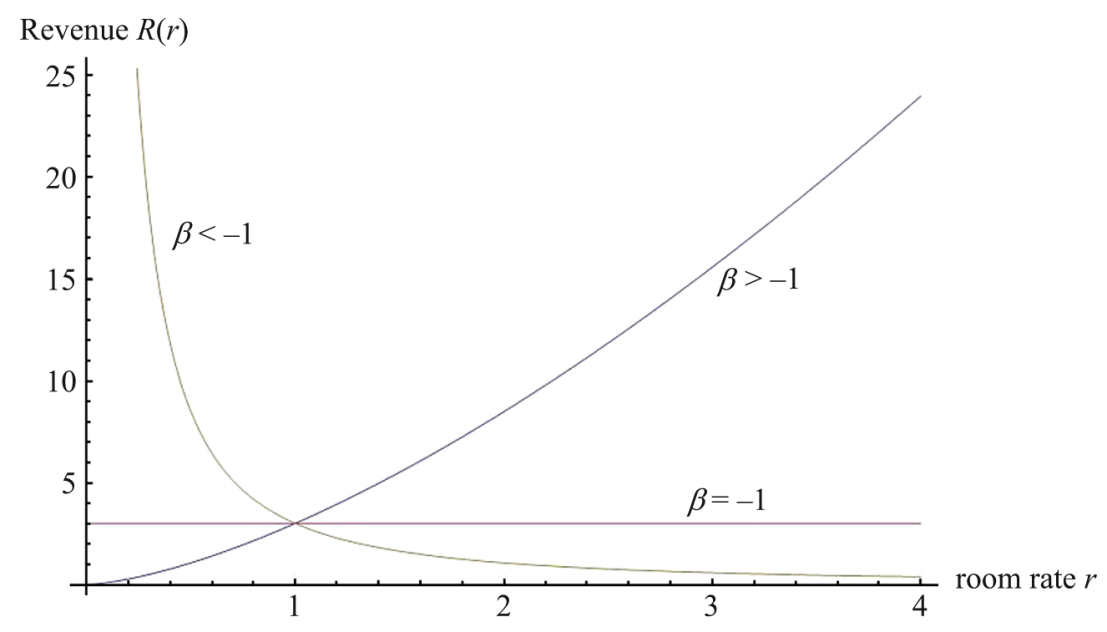

Figure 1. Revenue function for different values of $\beta$ 


\section{$\mathrm{IJCHM}$}

24,4

516
(2) The optimal room rate is a simple fixed multiple of the variable cost. For example, if the variable cost is doubled, then the optimal room rate will also double. Such a relationship between the optimal room rate and variable cost is rather extraneous.

(3) The optimal room rate is very sensitive to the variable cost when the elasticity is close to 1 . For example, for $e=1.05,1.1$, and $1.2, p^{*}$ is equal to $21 \mathrm{c}, 11 \mathrm{c}$, and $6 \mathrm{c}$, respectively. There is no rationale to support such a relationship.

We observe that the failure of the traditional calculus method to optimize either the revenue or the profit function based on the power model occurs because in reality the price and demand relation should only be considered within a certain limit. We know that the room rate $r$ will always take a value within certain reasonable intervals, and would never approach infinity or zero. We can thus exclude extreme cases of $r$ being very small or very large. After excluding the extreme cases, we can apply the following tangent method to the price-response function locally to arrive at the optimal room rate.

We must make the practical assumption that a hotel manager is able to determine a reasonable or equitable room rate, which is defined as the room rate calculated by using conventional methods. This is a reasonable assumption because, even without knowing the optimal room rate, hotels charge room rates that they believe to be most profitable. The room rates may be determined by budgeting or by benchmarking, and the process is often assisted by revenue management software and adjusted by experience and anticipation. Some hotels set the revenue budget at the beginning of a budget cycle, and determine their rooms rates based on budget and occupancy forecasts. Some hotels use market intelligence to find out the room rates of their competitors, and then determine their own rates by benchmarking. Most hotels adjust the benchmarking according to their bookings on hand and inventory. We assume that hotels are sufficiently experienced and educated to charge a room rate $r_{0}$ that is close to the optimal room rate.

For an $r$ close to $r_{0}$, the demand function can be approximated by the tangent line to the curve of the demand function $D(r)$ at $r=r_{0}$. The equation of this tangent line is given by:

$$
D_{0}(r)=D\left(r_{0}\right)+D^{\natural}\left(r_{0}\right)\left(r-r_{0}\right)
$$

Using this as the new demand function, the total revenue can be calculated by multiplying demand by price, which is given by:

$$
\begin{gathered}
R_{0}(r)=D_{0}(r) r \\
=\left(D\left(r_{0}\right)+D^{\natural}\left(r_{0}\right)\left(r-r_{0}\right)\right) r \\
=D^{\prime}\left(r_{0}\right) r^{2}+\left(D\left(r_{0}\right)-D^{\natural}\left(r_{0}\right) r_{0}\right) r
\end{gathered}
$$

Suppose that the cost function is $C(r)=D_{0}(r)+F$, where is the variable cost per room sold and $F$ is the fixed cost. The total profit function, $\pi_{0}(r)$, of revenue minus cost is then given by: 


$$
\begin{gathered}
\pi_{0}(r)=R_{0}(r)-\left(D_{0}(r) v+F\right) \\
=D_{0}(r) r-\left(D_{0}(r) v+F\right) \\
=D_{0}(r)(r-v)-F \\
=\left(D\left(r_{0}\right)+D^{\prime}\left(r_{0}\right)\left(r-r_{0}\right)\right)(r-v)-F \\
=D^{\prime}\left(r_{0}\right) r^{2}+\left(D\left(r_{0}\right)-D^{\prime}\left(r_{0}\right)\left(r_{0}+v\right)\right) r-v\left(D\left(r_{0}\right)-D^{\prime}\left(r_{0}\right) r_{0}\right)-F \\
=A r_{0}^{\beta-1}\left(\beta r^{2}+\left((1-\beta) r_{0}-\beta v\right) r-v(1-\beta) r_{0}\right)-F
\end{gathered}
$$

\section{Revenue management}

because $D(r)=A r^{\beta}$ and $D^{*}(r)=\beta A r^{\beta-1}$.

Note that $\pi_{0}(r)$ has a maximum at:

$$
\begin{gathered}
\pi_{0}^{\prime}(r)=0 \\
\Leftrightarrow 2 \beta r+\left((1-\beta) r_{0}-\beta v\right)=0 \\
\Leftrightarrow r=\frac{1}{2}\left(\left(1-\frac{1}{\beta}\right) r_{0}+v\right)
\end{gathered}
$$

which means that the total profit is maximized if the room rate is set to:

$$
r=\frac{1}{2}\left(\left(1-\frac{1}{\beta}\right) r_{0}+v\right)
$$

This solution indicates that the optimal room rate to achieve the maximum total profit is dependent on the elasticity $\beta$ and the variable cost per room sold, and does not depend on the value of $\mathrm{A}$.

\section{Example to illustrate optimization}

This section provides an example to illustrate the application of the derived optimization formula. Suppose that a hotel revenue management team wishes to determine the room rate that will maximize its profit. The hotel manager uses a conventional method to arrive at an equitable room rate $r_{0}$ of $\$ 950$, where the variable $\operatorname{cost} v$ is $\$ 145$. If data analysis suggests that a power model for the price-demand function is appropriate, then the manager can use formula (2) to adjust the room rate. There are three scenarios, depending on the value of $\beta$ :

- Scenario one: if $\beta=-1.55$, then $r=\frac{1}{2}\left(\left(1-\frac{1}{(-1.55)}\right) 950+145\right)=856$

- Scenario two: if $\beta=-1.18$, then $r=\frac{1}{2}\left(\left(1-\frac{1}{(-1.18)}\right) 950+145\right)=950$

- Scenario three: if $\beta=-0.95$, then $r=\frac{1}{2}\left(\left(1-\frac{1}{(-0.95)}\right) 950+145\right)=1050$

This example shows that if $r_{0}=950$ and $v=145$, then the suggested action to optimize the room rate depending on the value of $\beta$ is as follows (Table I).

\begin{tabular}{llll}
\hline-1.55 & -1.18 & -0.95 \\
\hline
\end{tabular}

Suggested action Lower room rate to $\$ 856$ Keep room rate at $\$ 950$ Raise room rate to $\$ 1,050$

The suggested action to optimize the room rate 
IJCHM

24,4

518

In fact, by solving the equation:

$$
r_{0}=\frac{1}{2}\left(\left(1-\frac{1}{\beta}\right) r_{0}+v\right),
$$

we arrive at the threshold value of -1.18 of $\beta$. The optimal rate should be higher (or lower) than the equitable rate of $r_{0}=950$ when $\beta$ is higher (or lower) than -1.18 .

\section{Conclusions and implications}

A review of the literature on hotel room rate optimization reveals that most existing research assumes an algebraic relationship between room rate and room demand, and that the optimal solution is obtained by applying calculus to the revenue or profit function. However, problems arise when this traditional method is applied to a model in which the demand function is a superior causal forecasting model in some markets, and the method gives an unrealistic solution. The paradox is that, on the one hand, we have a superior causal forecasting model based on room rates, yet on the other, the traditional method does not yield a realistic solution for room rate optimization. This study analyzes the underlying causes of this paradox and adopts a novel approach to resolve it.

The analysis in this study shows that the total profit is maximized when the room rate is set to:

$$
\frac{1}{2}\left(\left(1-\frac{1}{\beta}\right) r_{0}+v\right)
$$

where $\beta$ is a coefficient estimated by regression, $r_{0}$ is the initial equitable room rate determined by conventional methods, and $v$ is the variable cost per room sold.

This study reveals a problem that may arise with the traditional method of applying calculus to revenue and profit optimization, in that the solution so obtained overlooks the realistic limit for the price range and the applicability of the model outside this range. The problem is more pronounced when the traditional method is applied to the power model. The solution proposed in this study to resolve the paradox is both realistic and practical. It improves upon what hotel managers have in mind as the equitable room rate, and tells them by how much the rate should be adjusted upwards or downwards. The results are thus applicable both in practice and in theory.

The method developed in this study yields a viable, definitive, and realistic solution for the optimal room rate problem under certain assumptions, and in so doing contributes to the development of the theory of revenue management. The assumptions are:

- that hotel managers have historical data from which to estimate the room demand elasticity and the unit cost of operating a room; and

- that hotel managers are sufficiently wise to determine an equitable room rate that is close to the optimal room rate.

The first assumption is reasonable for hotels that make an effort to record historical room rates and occupancy. The elasticity can be estimated by regression, and a hotel manager should know the unit cost of operating a room. The second assumption is reasonable because, even without knowing the optimal room rate, a hotel manager 
charges room rates that he or she believes to be most profitable, and this is the equitable room rate.

The significance of this research method is that it can determine whether the room rate should be adjusted upward or downward to maximize the total profit, and arrive at a definitive value of the optimal room rate that will maximize the total profit. This study thus not only bridges the gap between practice and theory, but explicates the relationship between demand for hotel rooms and room rates hinted at in the literature review.

This study has several practical implications. First, it is absolutely crucial for hotels to make an accurate demand forecast based on price, and hence the price elasticity of demand, for the purposes of optimization. Second, conventional methods of determining the equitable room rate are still important, because the optimization process begins with the equitable room rate. Third, the proposed method can be used to enhance the equitable room rate determined by conventional methods, but does not replace intelligent human judgment. Finally, the study reveals the deficiency in the traditional method of applying calculus to the maximization of revenue and profit. This reminds us to be more cautious about the application of well established mathematical tools in the maximization of revenue and profit. As our study shows, the price range in which a model is applicable can be crucial to the optimization process, and overlooking this fact may lead to unrealistic solutions.

This study proposes the adoption of an econometric forecasting model to calculate the optimal room rate, and as such, the calculation depends on the accuracy of the forecasting model, and specifically the correctness of the estimated $\beta$ value. The authors acknowledge that the discussion is very much conceptual in nature, and requires the support of empirical data and warrants further research. The study also has the limitation that it does not deal with the different room types and rate categories in a hotel. To address this issue, a power model would need to be developed for each room type to depict the relationship between the room rate and demand, and the tangent method would then have to be applied to each power model to determine the optimal room rate. The optimization would be further complicated by the options of upgrading and downgrading.

\section{References}

Badinelli, R. (2000), “An optimal, dynamic policy for hotel yield management”, European Journal of Operational Research, Vol. 121 No. 3, pp. 476-503.

Baker, T. and Collier, D. (1999), "A comparative revenue analysis of hotel yield management heuristics”, Decision Sciences, Vol. 30 No. 1, pp. 239-63.

Bitran, G. and Mondschein, S. (1995), "An application of yield management to the hotel industry considering multiple day stays”, Operations Research, Vol. 43 No. 3, pp. 427-43.

Choi, S. and Kimes, S. (2002), "Electronic distribution channel's effect on hotel", Cornell Hotel and Restaurant Administration Quarterly, Vol. 43 No. 3, pp. 23-31.

Cross, R. (1997), "Launching the revenue rocket: how revenue management can work for your business", Cornell Hotel and Restaurant Administration Quarterly, Vol. 38 No. 2, pp. 32-43.

Cross, R., Higbie, J. and Cross, D. (2009), "Revenue management's renaissance: a rebirth of the art and science of profitable revenue generation”, Cornell Hospitality Quarterly, Vol. 50 No. 1, pp. 56-81. 
IJCHM

24,4

520
Enz, C., Canina, L. and Lomanno, M. (2009), "Competitive pricing decisions in uncertain times", Cornell Hospitality Quarterly, Vol. 50 No. 3, pp. 325-41.

$\mathrm{Gu}$, Z. (1997), "Proposing a room pricing model for optimizing profitability", International Journal of Hospitality Management, Vol. 16 No. 3, pp. 273-7.

Helsel, C. and Cullen, K. (2006), Defining Revenue Management: Top Line to Bottom Line, Hospitality Sales and Marketing Association International, Abu Dhabi.

Hong Kong Tourism Board (2008), Summary of the Hong Kong Hotel Industry Review 2008, Hong Kong Tourism Board, Hong Kong.

Hong Kong Tourism Demand Forecasting System (2009), "Global financial crisis and demand for hotel rooms in Hong Kong", available at: www.tourismforecasting.netreport.asp

Horwath HTL (2009), "China hotel industry report 2009”, Horwath HTL and China Tourist Hotel Association, Beijing.

Kimes, S. (2003), "Revenue management: a retrospective", Cornell Hotel and Restaurant Administration Quarterly, Vol. 44 Nos 5/6, pp. 131-8.

Lai, K.K. and Ng, W.L. (2005), "A stochastic approach to hotel revenue management”, Computers and Operations Research, Vol. 32 No. 5, pp. 1059-72.

Orkin, E. (1998), "Wishful thinking and rocket science", Cornell Hotel and Restaurant Administration Quarterly, Vol. 39 No. 4, pp. 15-19.

Pan, C.M. (2007), "Market demand variations, room capacity, and optimal hotel room rates", International Journal of Hospitality Management, Vol. 26 No. 3, pp. 748-53.

Phillips, R.L. (2005), Pricing and Revenue Optimization, Stanford Business Books, Stanford, CA.

PKF (2005), Trends in the Hotel Industry USA, PKF Consulting, Atlanta, GA.

Rajopadhye, M., Ghalia, M., Wang, P., Baker, T. and Eister, C. (2001), "Forecasting uncertain hotel room demand", Information Sciences, Vol. 132 Nos 1-4, pp. 1-11.

Relihan, W. (1989), "The yield-management approach to hotel-room pricing”, Cornell Hotel and Restaurant Administration Quarterly, Vol. 30 No. 1, pp. 40-5.

Rest, J.P.I. and Harris, P.J. (2008), "Optimal imperfect pricing decision-making: modifying and applying Nash's rule in a service sector context", International Journal of Hospitality Management, Vol. 27 No. 2, pp. 170-8.

Sanchez, J. and Satir, A. (2005), "Hotel yield management using different reservation modes", International Journal of Contemporary Hospitality Management, Vol. 17 No. 2, pp. 136-46.

Schwartz, Z. and Chen, C. (2010), "The peculiar impact of higher room rates on customers' propensity to book", International Journal of Contemporary Hospitality Management, Vol. 22 No. 1, pp. 41-55.

Song, H., Witt, S. and Li, G. (2009), The Advanced Econometrics of Tourism Demand, Routledge, London.

Song, H., Wong, K. and Chon, K. (2003), "Modelling and forecasting the demand for Hong Kong tourism", International Journal of Hospitality Management, Vol. 22 No. 4, pp. 435-51.

Song, H., Lin, S., Witt, S. and Zhang, X. (2011), "Impact of financial/economic crisis on demand for hotel rooms in Hong Kong", Tourism Management, Vol. 32 No. 1, pp. 172-86.

Steed, E. and Gu, Z. (2009), "Hotel management company forecasting and budgeting practices: a survey-based analysis", International Journal of Contemporary Hospitality Management, Vol. 21 No. 6, pp. 676-97.

Talluri, K.T. and Ryzin, G.J.V. (2005), The Theory and Practice of Revenue Management, Springer, New York, NY. 
Weatherford, L. (1995), "Length of stay heuristics: do they really make a difference?", Cornell Hotel and Restaurant Administration Quarterly, Vol. 36 No. 6, pp. 70-9.

Weatherford, L. and Kimes, S. (2003), “A comparison of forecasting methods for hotel revenue management", International Journal of Forecasting, Vol. 19 No. 3, pp. 401-15.

Weatherford, L., Kimes, S. and Scott, D. (2001), "Forecasting for hotel revenue management: testing aggregation against disaggregation", Cornell Hotel and Restaurant Administration Quarterly, Vol. 42 No. 4, pp. 53-64.

\section{Corresponding author}

Tony S.M. Tse can be contacted at: hmttse@polyu.edu.hk
Revenue management

521

To purchase reprints of this article please e-mail: reprints@emeraldinsight.com Or visit our web site for further details: www.emeraldinsight.com/reprints 